\title{
A New Trend of Physical Concentration in Resources Recycling
}

\section{Shuji Owada}

Faculty of Science and Engineering, Waseda University; Okubo 3-4-1, Shinjuku-ku, Tokyo, 169-8555, Japan E-mail: owadas@waseda.jp

\begin{abstract}
Physical separation is one of the key technologies in the field of resources recycling for concentrating targeted component(s) and could create an environment friendly recycling process because of their relatively low energy consumption and low cost required. Physical separation process involves two kinds of stages, one is comminution for achieving the liberation of targeted component(s) and the other is real separation of target component(s) from the others. Recently a variety of smart comminution processes, involving mechanical and electrical disintegration as well as the pre-treatment, is developed for aiming selective breakage of phase boundaries of the solid materials to be recycled. The paper indicated several examples of such processes, (1) selective mechanical comminution for effective utilization of aluminum dross, (2) two-stage comminution for recovering minor rare metals from electronic appliances, and (3) concentration of platinum group metals from spent automobile catalyst. The paper also mentioned a sensor based sorting (SBS) process by combining several sensing systems, XRT and XRF, to achieve a horizontal recycling of scrap aluminum.
\end{abstract}

Keywords: Smart comminution, electrical disintegration, sensor based sorting, horizontal recycling.

ENGINEERING JOURNAL Volume 20 Issue 4

Received 3 March 2016

Accepted 13 June 2016

Published 1 August 2016

Online at http://www.engj.org/

DOI:10.4186/ej.2016.20.4.129 


\section{Introduction}

In order to establish sound material cycle society, some energy saving and low cost processing methods are required. Physical separation is one of the candidate technologies but this technology has been understood for a long time not a reliable, accurate and predictable one. This paper pointed out the reason of this understanding, mentioned theoretical background, and demonstrated a future possibility of the physical separation.

The paper also introduced some brand new processes recently developed by the authors, involving, (1) selective mechanical comminution for effective utilization of aluminum dross, both to produce high purity metal aluminum concentrate and to generate hydrogen molecule, (2) two-stage comminution for removing printed circuit board (PCB) from the electronic appliances by specific mechanical comminution in the first stage and for detaching the devices on the PCB by mechanical and/or electrical disintegration to concentrate minor rare metals, (3) concentration of platinum group metals from spent automobile catalyst by combining heating-quenching and surface grinding, and (4) combination of several sensing systems, such as X-ray transmission, X-ray fluorescence, as a novel sensor based sorting (SBS) process for creating a horizontal recycling of aluminum resource. In conclusion, a new concept of recycling process was represented for minimizing total required energy and cost by combining smart comminution and the SBS technologies.

\section{Comminution for Liberation}

It is well understood in the field of resources recycling that wider application and further improvement of physical separation technology is necessary in order to create an energy saving and low cost process. Comminution technology, the first step of physical separation, must be one of the most important unit operations for achieving good liberation of target components from others. Figure 1 shows a theoretical relationship [1] between comminution ratio and the degree of liberation at various preferential breakage probability at phase boundary, e1. If the breakage is at random $(\mathrm{e} 1=0)$ in a comminution process, comminution ratio of 5.9 is necessary to obtain the degree of liberation 0.6 , but if the e1 could become 0.1 , $0.2,0.3$, and 0.4 , the necessary comminution ratio to obtain the same liberation was reduced down to 3.6, 2.7, 2.1, and 1.6, which indicate that the necessary energy could be down to the same ratio.

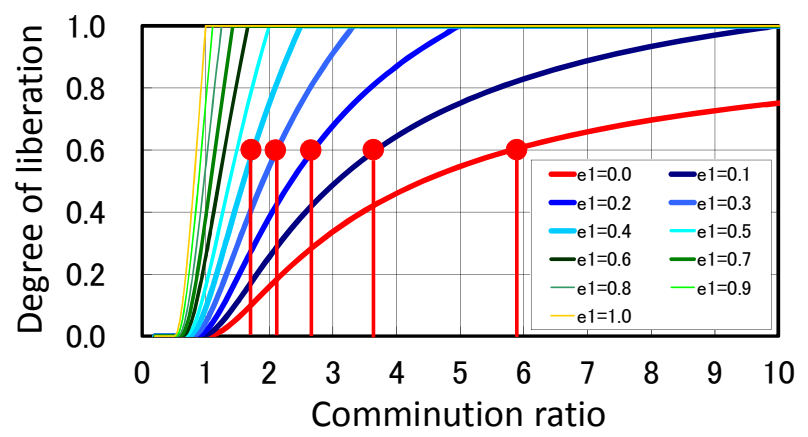

Fig. 1. Relationship between comminution ratio and the degree of liberation at various preferential breakage probability at phase boundary, e1 [1].

Several types of mechanical crushers, surface grinding, electrical disintegration, etc. are such comminution technologies to increase the selectivity of breakage. Typical examples will be indicated later.

\section{Sensor Based Sorting (SBS)}

Sensor based sorting is now called the "New Revolution of Physical Separation" after the quarter of century in which eddy current separator was developed. Recent sensing system has been rapidly improved in addition to upgrading software technology and much more precise analysis, combining size, shape, color, density, luster, density, chemical composition, etc., have been carried out in one sorting process. Figure 2 shows various detecting systems which have been commercialized until now. It must be possible to 
separate precisely by combining various sensing methods even in the physical separation process (see Fig. $3)$.

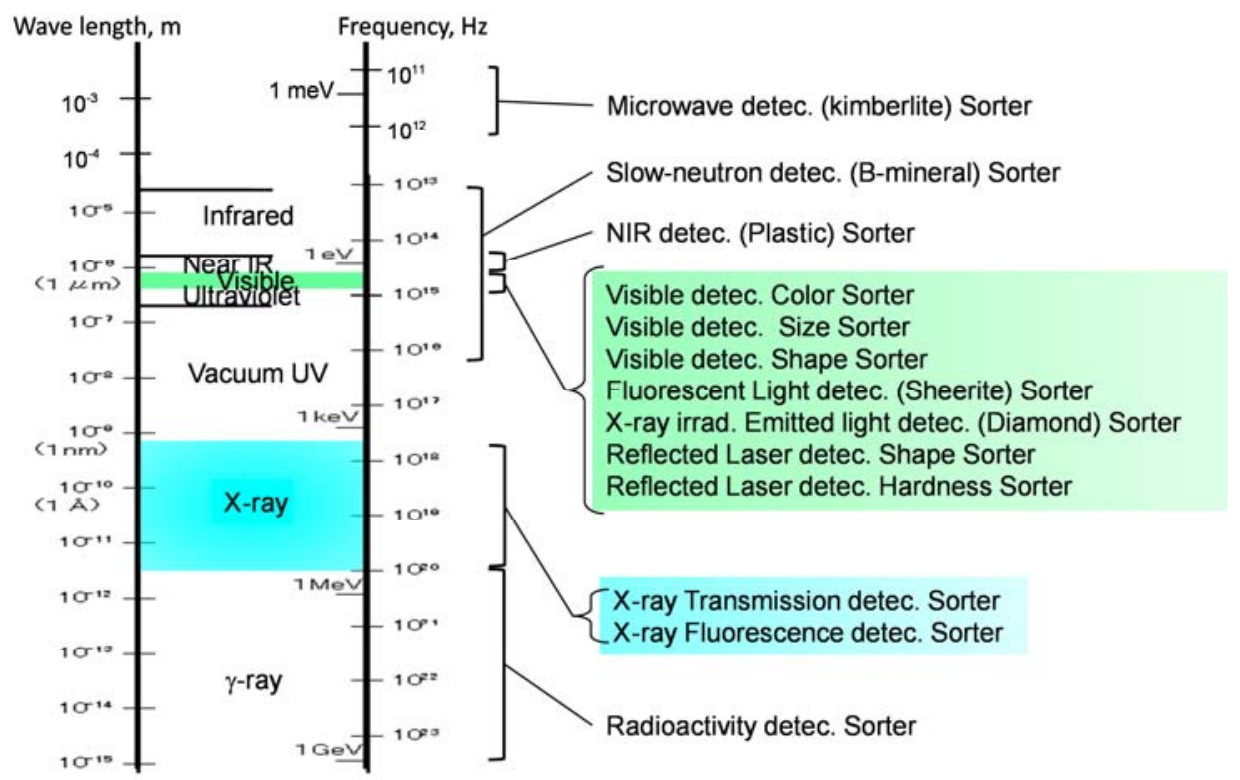

Fig. 2. Various commercialized sorting systems [2].

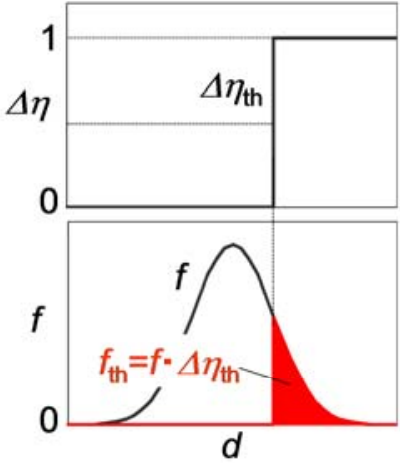

Ideal separation and SBS

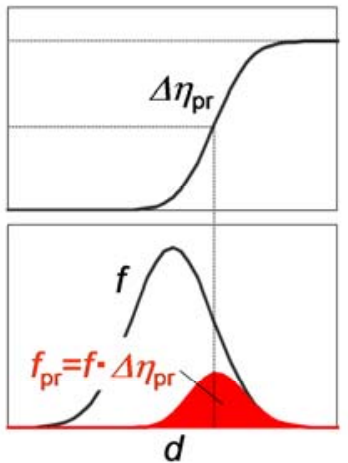

Real separation

Fig. 3. Ideal and real physical separation performance.

Recently, LIBS (laser induced breakdown spectroscopy) analysis has become an interesting detecting system also for sorting and will be able to be a strong method to identify the materials to be recovered near in the future [3-7].

\section{Future Physical Separation Process}

From the above viewpoint, novel physical separation process could be established as shown in Fig. 4 in which the target materials could be liberated in coarser size ranges as much as possible and the SBS technology could be applied for obtaining high purity concentrates as shown in Fig. 4 [4]. It must be also possible to replace some of the pyro-metallurgical technologies, which require huge amount of energy, into these smart comminution and novel SBS technologies (see Fig. 5) [5]. Huge amount of total energy could be saved if these kinds of processes are established near in the future. 


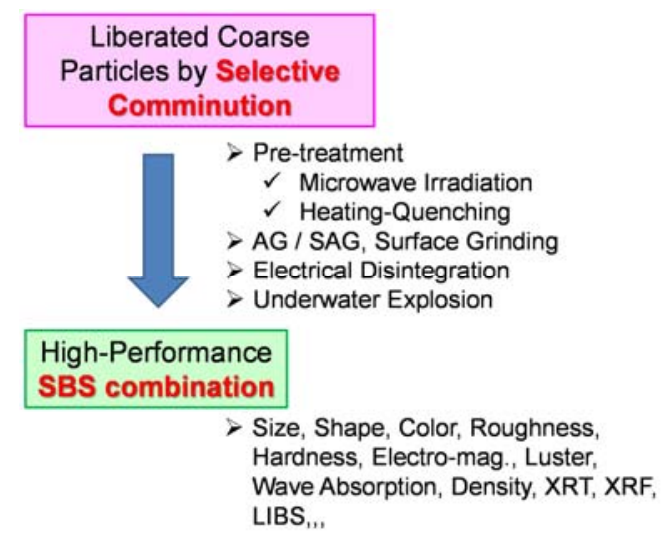

Fig. 4. Future physical separation process [8].
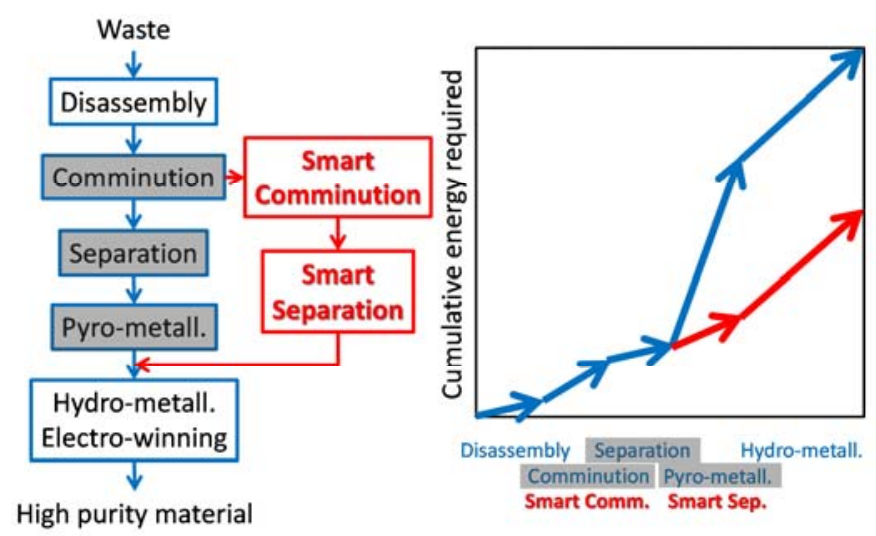

Fig. 5. Energy saving by applying novel physical separation [8].

\section{Examples of Novel Process in the Field of Resources Recycling}

\subsection{Selective Mechanical Comminution for Effective Utilization of Aluminum Dross}

Aluminum dross must be one of the troublesome wastes generated from scrap aluminum treatment. However, we can create a novel process to produce from the dross two kinds of valuable materials, one is raw material to recover high purity metal aluminum and the other is that to produce hydrogen molecule. In the process, important is the application of selective grinding and electrical separation technologies (eddy current and electrostatic separation). In the latter case, 1.5 molar of hydrogen molecule and 1.0 molar of $\mathrm{Al}$ $(\mathrm{OH})_{3}$ could be produced from 1.0 molar metal aluminum in the dross, as shown in the following equations.

$$
\begin{aligned}
& \mathrm{Al}+\mathrm{NaOHaq}+3 \mathrm{H}_{2} \mathrm{O} \rightarrow \mathrm{Na}\left[\mathrm{Al}(\mathrm{OH})_{4}\right]+3 / 2 \mathrm{H}_{2}(\mathrm{~g}) \ldots \text { (1) } \\
& \left(\Delta \mathrm{G}_{\mathrm{r}, 298}^{0}=-437.8 \mathrm{kJmol}^{-1}, \Delta \mathrm{H}_{\mathrm{r}, 298}^{0}=-415.5 \mathrm{kJmol}^{-1}\right) \\
& \mathrm{Na}\left[\mathrm{Al}(\mathrm{OH})_{4}\right] \mathrm{aq} \rightarrow \mathrm{Al}(\mathrm{OH})_{3}+\mathrm{NaOHaq} \\
& \left(\Delta \mathrm{G}_{\mathrm{r}, 298}^{\mathrm{a}}=10.5 \mathrm{kJmol}^{-1}, \Delta \mathrm{H}_{\mathrm{r}, 298}^{0}=-3.2 \mathrm{kJmol}^{-1}\right) \\
& \text { Total reaction } \\
& \mathrm{Al}+3 \mathrm{H}_{2} \mathrm{O} \rightarrow \mathrm{Al}(\mathrm{OH})_{3}+3 / 2 \mathrm{H}_{2}(\mathrm{~g}) \\
& \left(\Delta \mathrm{G}_{\mathrm{r}, 298}^{0}=-427.3 \mathrm{kJmol}^{-1}, \Delta \mathrm{H}_{\mathrm{r}, 298}^{0}=-418.7 \mathrm{kJmol}^{-1}\right)
\end{aligned}
$$

$\mathrm{NaOH}$ generated in the reaction (2) could be circulated to the reaction (1), and the generated heat from the reactions (1) and (2) could be used to operate the pilot plant which has a dewatering and drying process of $\mathrm{Al}(\mathrm{OH})_{3}$. 
The treatment flow is shown in Fig. 6. In this process, we could separate two kinds of products from the aluminum dross of $46.2 \mathrm{wt} \%$ of metal aluminum, one is for the metal aluminum recovery whose grade is $90.9 \mathrm{wt} \%$ metal aluminum with the recovery of $35.3 \%$ and the other is for the hydrogen generation whose grade is $21.6 \mathrm{wt} \%$ metal aluminum with the recovery of $64.7 \%$ [9]. These results was found feasible from the viewpoints of the life cycle assessment and cost analysis compared with conventional processes.

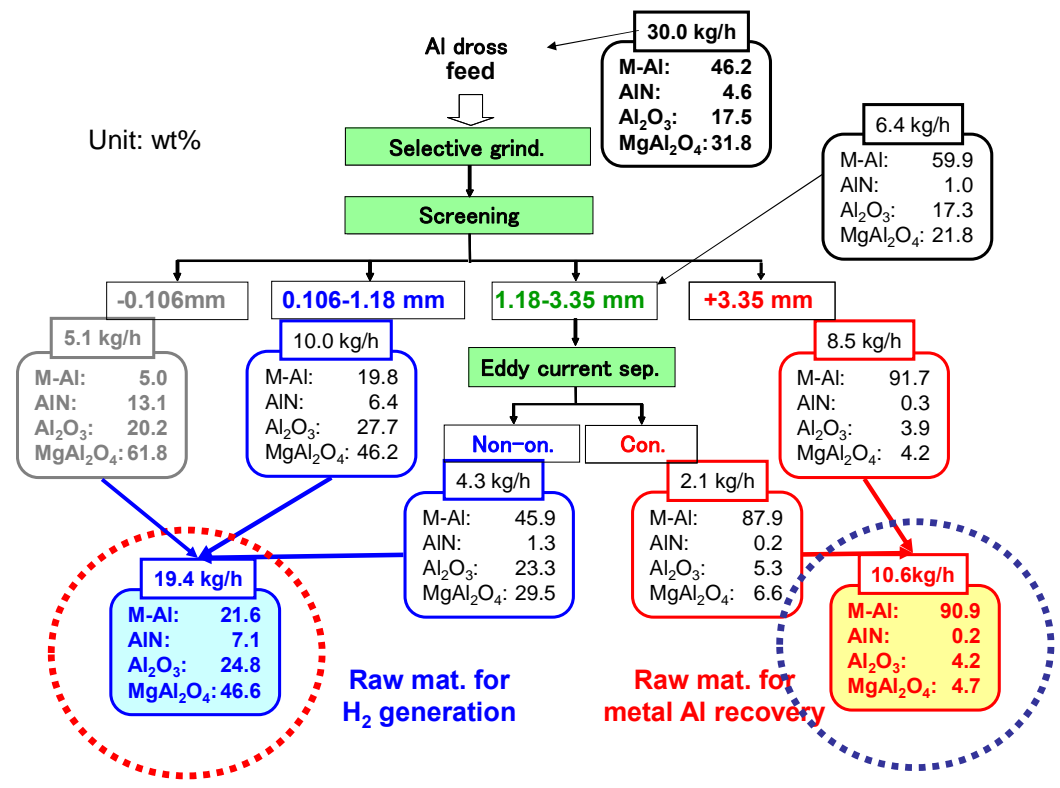

Fig. 6. Treatment flow of the aluminum dross to produce two kinds of raw materials.

\subsection{Two-Stage Comminution for Concentrating Minor Rare Metals}

In order to concentrate minor rare metals in the printed circuit board (PCB), we applied two-stage comminution process, the first one is for removing the PCB from the body and the second one is for detaching specific devices from the PCB. In the second stage crushing, six kinds of crushers and conditions were applied and it has been clarified that the crushers in which the shear force was applied to the samples predominantly were suitable to remove installed devices form PCBs. Electrical disintegration was also tried to this stage and this method made a best performance to remove devices from PCBs in nondestructive form for small devices and to break/liberate compositional metal phases for large devices. Many kinds of devices, such as Ta capacitors [10] etc. could be concentrated in high purity grade with high recovery by combining physical separation, such as sizing, magnetic separation, pneumatic separation. These concentrates must be good resources of minor rare metals.
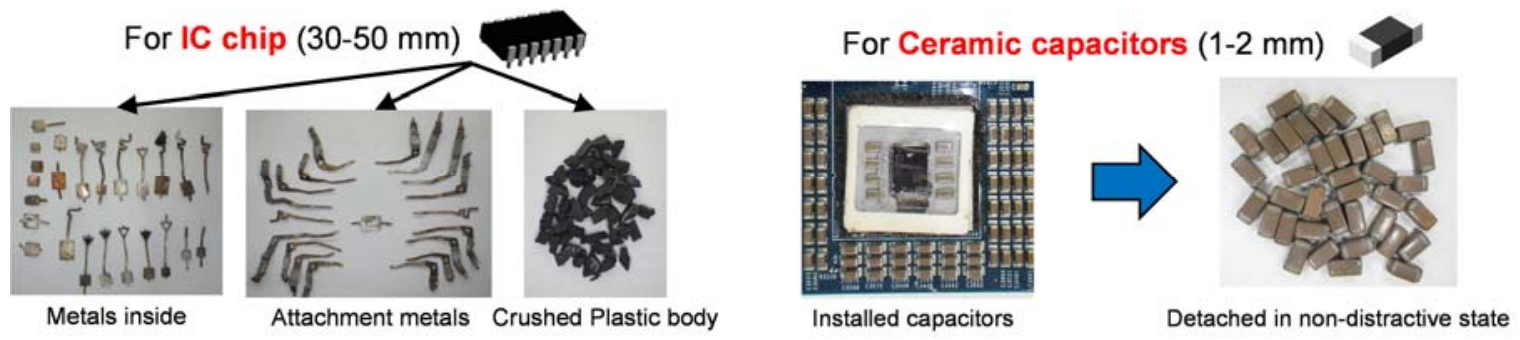

Fig. 7. Crushed product with electrical disintegration (ED) for the devices on PCB.

\subsection{Heating-Quenching for Concentrating PGMs from Spent Automobile Catalyst}

Spent automobile catalysts still have considerable amount of platinum group metals (PGMs, which are Pt, $\mathrm{Pd}$ and $\mathrm{Rh}$ ) to be recovered are existent. Present major recycling process is called "Rose process" in which the catalysts are first finely ground the PGMs are concentrated into molten $\mathrm{Cu}$ phase. This process is quite 
reasonable to achieve high recovery of PBMs but required energy is huge. We are developing a novel process involving heating-quenching and selective grinding to concentrate PGMs as an energy saving process by utilizing specific catalyst structure, in which cordierite substrate are covered by the aggregates of fine alumina particles containing PGMs (see Fig. 8(a)). In the process, alumina could be easily removed and PGMs are concentrated from cordierite and the load of energy consuming pyro-metallurgical process could be reduced into 20 to $30 \%$. Figures 8 (b) and (c) shows the temperature distribution of stress in the catalyst and stress applied to the alumina and cordierite in the quenching. It is clear that the tensile stress could be applied to alumina and compressive stress to cordierite, then, the breakage easily occurs in the alumina but not in cordierite. From detailed microscopic observation, the micro-cracks are generated at the phase boundary and in alumina. From this selective grinding process including heating-quenching, 45.8 $\mathrm{wt} \%$ of alumina phase could be concentrated with the recovery of $85.7 \%$ [11]. The remaining alumina phase (PGMs) could be recovered with relative ease by a flotation with some anionic collectors because the PZC of alumina is much higher than that of cordierite.

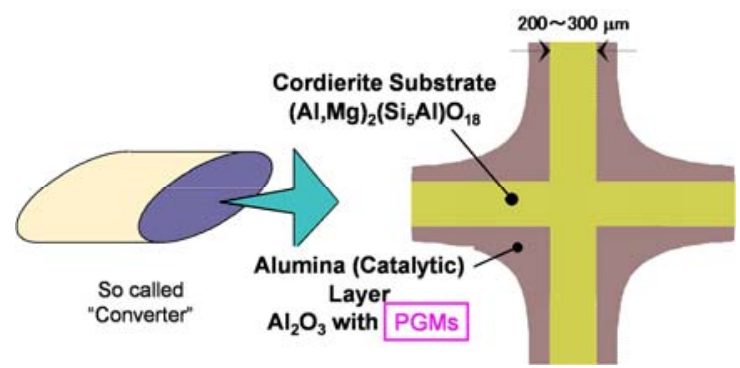

(a)

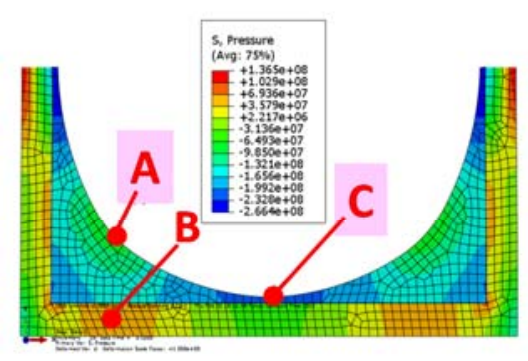

Thermal stress distribution at $0.5 \mathrm{~s}$

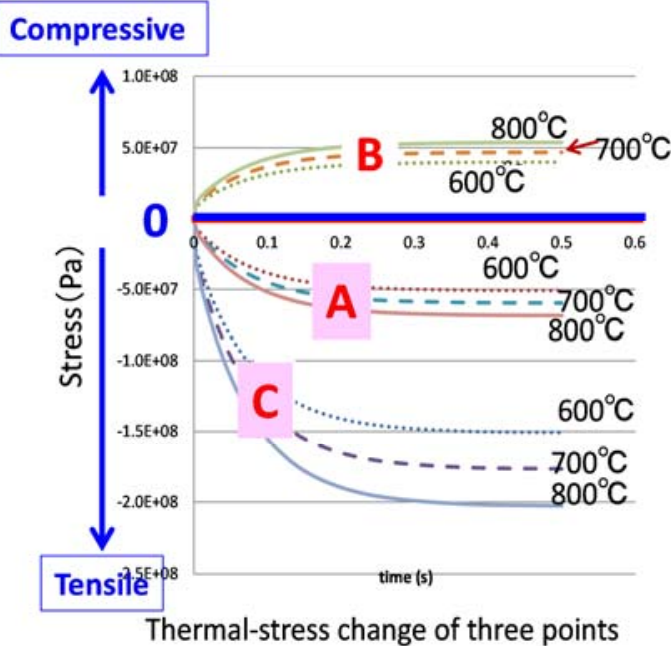

(c)

Fig. 8. (a) Structure of automobile catalyst, (b) Thermal distribution of the half cell in quenching, (c) Stress applied in heating-quenching process [11].

\subsection{XRT and XRF Sorting Process for the Mutual Separation of Aluminum Alloys}

Most of the scrap aluminum is usually mixed and melted for the use as casting raw materials which contain much amount of various alloy elements and is never recycled into wrought materials again in Japan. If the mixed aluminum alloys are separated from each other with high efficiency, the products could be reutilized as wrought materials which must be a "horizontal recycling" as shown in Fig. 9. In order to achieve this novel route, we have applied three kinds of sorting technologies of electro-magnetic, X-ray transmission and X-ray fluorescence (see Fig. 10). We constructed a pilot plant at a private company in a national project and over $99 \mathrm{wt} \%$ grade 6063 alloy product was obtained with the recovery of over $94 \%$ which was a sufficient result for commercial use [12]. 


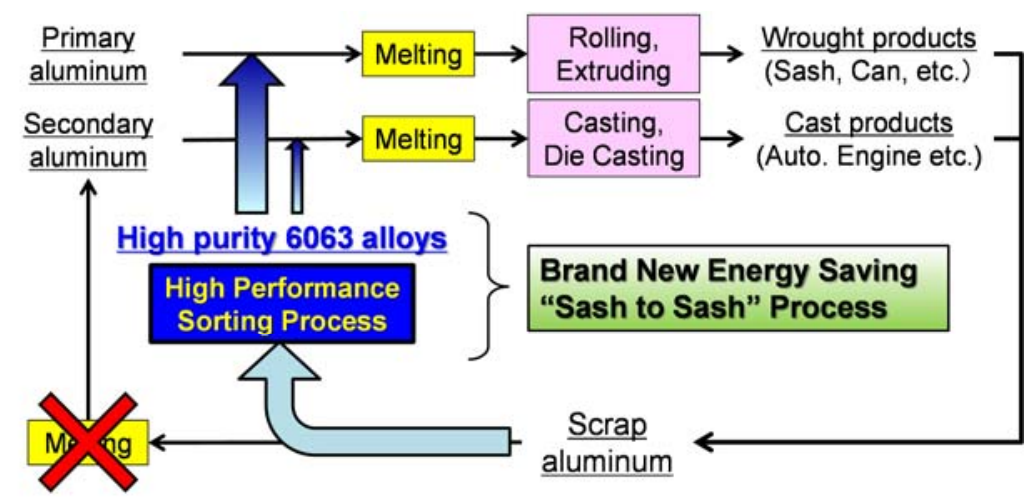

Fig. 9. Novel process for horizontal recycling of $\mathrm{Al}$ resources [12].

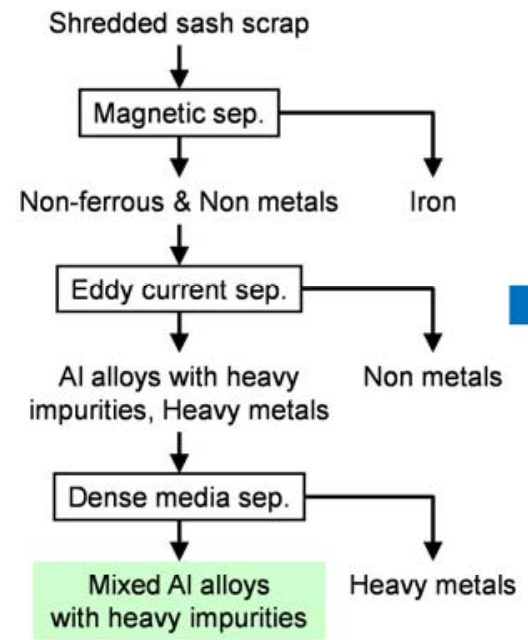

$<$ Conventional Process $>$

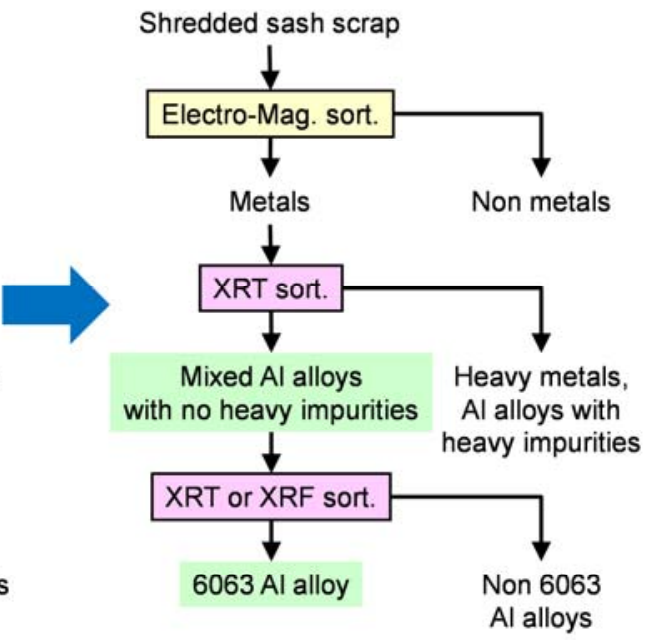

$<$ Novel Process $>$

Fig. 10. Novel process for recovering high purity $6063 \mathrm{Al}$ alloy from mixed scrap alloys.

\section{References}

[1] S. Owada, M. Ito, K. Naraki, K, Takeda, K, Kurokawa, and T. Omiya, "Novel liberation model considering preferential breakage at phase boundary and the experimental validation," J. MMIJ, vol. 121, no. 1, pp. 28-33, 2005.

[2] S. Owada, "Elemental technologies for optimizing aluminum circulation and the application," Technical Committee of Life Cycle Engineering, The Japan Society for Precision Engineering, pp.1-23, 2012.

[3] R. Noll, Laser-Induced Breakdown Spectroscopy, Springer, p.7-12, p.75-81, p.83-95, 2012

[4] Y. Goto, T. Hatano, S. Owada, K. Wagatsuma, and S. Kashiwakura, "Mutual separation of nonferrous metals by LIBS and the applicability to sorting system," Spring meeting-MMIJ, pp.1-6, 2014.

[5] S. Owada, "Summary of activities of physical separation group -electrical disintegration and LIBS sorting," Fall meeting-MMIJ, pp.1-6, 2014

[6] T. Hatano, S. Owada, K. Wagatsuma, and S. Kashiwakura, "Influence of various parameters in LIBS aiming the application to sorting," Spring meeting-MMIJ, pp.1-6, 2015.

[7] S. Kashiwakura, and K. Wagatsuma, "Rapid sorting of stainless steels by open-air laser-induced breakdown spectroscopy with detecting chromium, nickel, and molybdenum," ISIJ International, 2015.

[8] S. Owada, "Demand and expect to the SURE consortium," Kick-off meeting of SURE, AIST, pp.1-37, 2014.

[9] S. Owada, and M. Katsuta, "On the project of establishing G-Hydrogen based society in HonjoWaseda area," Resources Processing, vol. 51, no. 4, pp. 204-208, 2004. 
[10] S. Owada, T. Komuro, T. Ono, R. Hayashi, and C. Tokoro, "Concentration of minor rare metals from e-scraps by combining new comminution and physical separation processes," EARTH 2013 (best paper award), Zhangjiajie, China, pp.787-791, 2013.

[11] G. F. Liu, and S. Owada, "Concentration of PGMs from spent automobile catalyst by combining heating-quenching and selective grinding," paper no.8883, pp.1-11, 2015.

[12] S. Owada, K. Tsuchiya, A. Takasugi, Y. Kato, T. Funakoshi, and H. Tanno, "Novel process of aluminum recycling by combining XRT and XRF sorting," Sensor Based Sorting 2012, Aachen, pp.1-7, 2012. 